\title{
UNINTENDED CONSEQUENCES: PROHIBITIONS ON Gamete Donor ANONYMity and the Fragile PRACTICE OF SURROGACY
}

\author{
GAIA BERNSTEIN ${ }^{*}$
}

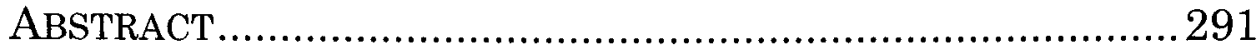

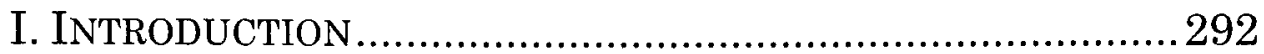

II. THE PRACTICE OF SURROGACY ……………………........297

III. The IMPACT OF PROHIBITIONS ON GAMETE DONOR

ANONYMITY ON GAMETE SUPPLIES................................299

IV. A PREFERENCE FOR GESTATIONAL SURROGACY ...............308

A. Legal Preference .....................................................308

B. Medical Practioners' Preference .................................. 315

V. Potential Ramifications of Prohibition on Gamete

DONOR ANONYMity ON THE PRACTICE OF SURROGACY . 318

A. Return to Traditional Surrogacy ................................318

B. Refrain from Surrogacy Altogether ............................321

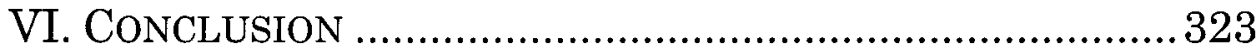

\section{ABSTRACT}

Prohibitions on anonymous egg and sperm donations are a growing international trend. U.S. law does not prohibit anonymous gamete donations. However, an expanding movement is advocating a shift to an open identity regime that will ban anonymity. My earlier study of three jurisdictions: Sweden, Victoria (Australia) and the United Kingdom, which adopted prohibitions on gamete donor

* Professor of Law, Seton Hall University School of Law. For their invaluable comments, I owe thanks to Judith Daar, Theresa Glennon and the participants of the following conferences: the International Law Association Meeting at Fordham Law School, the Imagining the Next Quarter Century of Health Care Law Symposium at the Robert $\mathrm{H}$. McKinney School of Law, Indiana University, the Baby Markets conference at the Indiana University Maurer School of Law, and the Health Law Professors Conference at Arizona State University. I would also like to thank Laura Green, Jeanne O'Connor, Julie Rich, Eric Suggs and Meredith Traina for their excellent research assistance. 
anonymity, showed that these prohibitions played a role in creating shortages in egg and sperm supplies. Adoption of prohibitions on anonymity in the United States could result in similar shortages.

This article focuses on the potential effects of prohibitions on anonymity on the practice of surrogacy. The practice of surrogacy in the United States is highly dependent on donor eggs. Unlike most jurisdictions that prohibit gamete donor anonymity, the majority of U.S. states that permit surrogacy, distinguish between gestational and traditional surrogacy. In traditional surrogacy, the surrogate uses her own eggs and is the genetic mother of the conceived baby. However, in gestational surrogacy, the eggs of the intended mother or a donor are used and the surrogate is not the genetic mother. Donor eggs are used only in gestational surrogacy but not in traditional surrogacy. States that distinguish between traditional and gestational surrogacy provide legal certainty only to gestational surrogacy while leaving traditional surrogacy in a legal limbo. Infertility practitioners endorse the legal preference for gestational surrogacy..

This article advises that a shift toward an open identity system in the United States should be considered with extra caution because of the potential consequences to the practice of surrogacy. Prohibitions on gamete donor anonymity causing a scarcity in donor eggs could force a return to traditional surrogacy, with the accompanying legal uncertainty. Alternatively, the legal uncertainty enveloping traditional surrogacy could deter those in need of surrogacy from seeking it altogether thereby significantly contracting the practice of surrogacy.

\section{INTRODUCTION}

Prohibitions on gamete donor anonymity are a growing international trend. Since 1985, eleven jurisdictions: Sweden, Austria, Switzerland, the Netherlands, Norway, the United Kingdom, New Zealand, Finland, and the 
Australian states of Victoria, Western Australia, and New South Wales have prohibited anonymous gamete donations. ${ }^{1}$ In addition, a prohibition on gamete donor anonymity is currently being litigated in Canada, following a judicial decision prohibiting anonymity ${ }^{2}$ In these jurisdictions, egg and sperm donors are not anonymous. Instead, typically, when the child conceived through gamete donation reaches the age of eighteen, he can receive the identifying information of his genetic parents - the sperm or egg donor.

U.S. law does not prohibit anonymous gamete donation. ${ }^{3}$ However, a growing movement of commentators is advocating a shift to an open identity model that would ban anonymity. ${ }^{4}$ Furthermore, in 2011, Washington State was the first U.S. state to adopt a modified open identity statute. ${ }^{5}$ The Washington statute makes open identity the default option, unless donors opt out. However, even if a

$1 \quad$ Eric Blyth \& Lucy Frith, Donor-Conceived People's Access to Genetic and Biographical History: An Analysis of Provisions in Different Jurisdictions Permitting Disclosure of Donor Identity, 23 INT'L J. L. POL'Y \& FAM. 174, 174-76 (2009) [hereinafter Disclosure of Donor Identity].

2 See Pratten v. British Columbia (Att'y Gen.), 2011 BCSC 656, ๆ 215 (Can.).

3 See NaOmi R. CAHn, Test Tube Families: Why the Fertility Market NEeds Legal REgulation 115 (2009) [hereinafter Test Tube FAMILIES].

4 See generally id. at 114-29, 215-37; Naomi Cahn, Necessary Subjects: The Need for a Mandatory National Donor Gamete Databank, 12 DePaul J. Health CARe L. 203 (2009) [hereinafter Necessary Subjects]; Michelle Dennison, Revealing Your Sources: The Case for Non-Anonymous Gamete Donation, 21 J.L. \& HealTh 1, 3 (2007-08); Mary Lyndon Shanley, Collaboration and Commodification in Assisted Procreation: Reflections on an Open Market and Anonymous Donation in Human Sperm and Eggs, 36 LAW \& SoC'Y REv. 257 (2002). But see Mary Patricia Byrn \& Rebecca Ireland, Anonymously Provided Sperm and The Constitution, 23 CoLUM. J. GENDER \& L. 1 (2012) (pointing out that banning anonymity poses constitutional issues).

5 BONNIE ROCHMAN, WHERE DO (SOME) BABIES COME FROM? IN WASHINGTON, A NEW LAW BANS ANONYMOUS SPERM AND EGG DONORS, Time Magazine, JUL. 22, 2011, HTTP://HEALTHLAND.TIME.COM/2011/07/22/ WHERE-DO-SOME-BABIES-COME-FROM-IN-WASHINGTON-A-NEW-LAW-BANSANONYMOUS-SPERM-AND-EGG-DONORS/. 
donor opts out of disclosing his identifying information to the conceived child, his medical records remain available. ${ }^{6}$ As the debates on gamete donor anonymity gain steam, they usually focus on the privacy and procreative liberty interests of the parents, the privacy interests of the donors, the best interests of the born children and the effects on the supply of donor gametes. ${ }^{7}$ In a previous study, I have explored the impact of prohibitions on gamete donor anonymity on the supplies of egg and sperm and the potential effect on the broad population of fertility patients in need of donor gametes. ${ }^{8}$ This article addresses unexplored aspect of the gamete supply problem, which is practically unique to the United States, and which could

6 See WASH. REv. CODE § 26.26.750 (2012).

7 For discussions of the interests of the children, see TEST TUBE FAMILIES, supra note 3, at 218-20; Jean Benward et al., Maximizing Autonomy and the Changing View of Donor Conception: The Creation of a National Donor Registry, 12 DePaUl J. Health CaRe L. 225, 232-34 (2009); Naomi Cahn, The New Kinship, 100 GEO. L.J. 367 (2012); Dennison, supra note 4, at 14-16; Glenn Cohen, Regulating Reproduction: The Problem with Best Interests, 96 MINN. L. REV. 423, 461-65 (2011) [hereinafter Best Interests]; Glenn Cohen, Response: Rethinking Sperm-Donor Anonymity: Of Changed Selves, Nonidentity, and One-Night Stands, 100 GEO. L.J. 431 (2012) [hereinafter Response]; Shanley, supra note 4, at 268-70. For discussion of additional interests, see Gaia Bernstein, Regulating Reproductive Technologies: Timing, Uncertainty and Donor Anonymity, 90 B.U. L. REV. 1189, 1205-1218 (2010) [hereinafter Regulating Reproductive Technologies] (revealing the impact of prohibitions on gamete donor anonymity on gamete supplies in Victoria, Sweden, and the United Kingdom); Glenn Cohen \& Travis G. Coan, Can You Buy Sperm Donor Identification? An Experiment (Harvard Law Sch. Pub. Law \& Legal Theory Research Paper Series, Working Paper No. 12-36, 2012), available at http://papers.ssrn.com/sol3/papers.cfm?abstract_id=2109550\#\%23

(examining the effect of prohibitions on anonymity on compensation for gamete donations); Lucy Frith, Gamete Donation and Anonymity: The Ethical and Legal Debate, HUM. REPROD. 818, 820-22 (2001) (discussing the interests of parents and children); Sonia M. Suter, Giving in to Baby Markets: Regulation Without Prohibition, 16 MICH. J. GENDER \& L. 217, 260-73 (2009) (discussing the interests of parents, donors, and children); Ilke Turkmendag, Robert Dingwall \& Therèse Murphy, The Removal of Donor Anonymity in the UK: The Silencing of Claims of Would-Be Parents, 22 INT'L J. L. POL'Y \& FAM. 283, 292 (2008) (emphasizing the neglect of the interests of the parents under the new U.K. policy).

8 Bernstein, supra note 7 , at $1205-18$. 
affect a subset of individuals in need of gamete donation fertility patients who require both egg donation and a surrogate in order to have a child. This article examines the way in which adoption of prohibitions on gamete donor anonymity in the United States could affect gamete supplies and unintentionally destabilize the practice of surrogacy.

My earlier study of Victoria (Australia), Sweden and the United Kingdom, each of which adopted prohibitions on gamete donor anonymity, revealed a disconcerting picture of the effect of these prohibitions on gamete donor supplies. Although the data is inconsistent at times, all three jurisdictions suffer from significant shortages in donor gametes accompanied by long wait-lists for recipients. Although the prohibition on gamete donor anonymity is not necessarily the only factor leading to a shortage in donor gametes, it appears to have played an important role in creating these shortages. ${ }^{9}$

Surrogacy practice in the United States is highly dependent on donor eggs. There are two types of surrogacy arrangements. The first is traditional surrogacy, in which the surrogate is inseminated with sperm from the male partner of the intended parents or with donor sperm. In this type of surrogacy the surrogate's eggs are used and she is the genetic mother of the child she carries. ${ }^{10}$ The second type is gestational surrogacy, in which the surrogate carries an embryo created through in vitro fertilization (IVF) with the sperm and eggs of the intended parents or donors. In this type of surrogacy the surrogate is not the genetic mother of the baby because her eggs are not used. ${ }^{11}$

Gestational surrogacy often involves donor eggs, not the intended mother's eggs. The most recent available data

$9 \quad I d$.

10 Janice C. Ciccarelli \& Linda J. Beckman, Navigating Rough Waters: An Overview of Psychological Aspects of Surrogacy, 61 J. Soc. ISSUES 21, 21 (2005); AMERICAN SOCIETY FOR REPRODUCTIVE MEDICINE, THIRD PARTY REPROdUCTION: A GUIDE FOR PATIENTS 13 (2012), available at http://www.reproductivefacts.org/uploadedFiles/ASRM_ Content/Resources/Patient_Resources/Fact_Sheets_and_Info_Booklets/ thirdparty.pdf.

11 Ciccarelli \& Beckman, supra note 10; AMERICAN SOCIETY FOR REPRODUCTIVE MEDICINE, supra note 10, at 13. 
shows that $46 \%$ of reported IVF cycles for surrogacy involved donor eggs. Furthermore, donor eggs are usually eggs of younger women, and are, therefore, more likely to produce a pregnancy and a live birth through surrogacy, than cycles using the intended mother's eggs. ${ }^{12}$ Yet, while gestational surrogacy is highly dependent on donor eggs, the United States, unlike most other jurisdictions that prohibit gamete donor anonymity, legally differentiates between gestational surrogacy and traditional surrogacy (which does not require donor eggs of a third party). Currently, fifteen states clearly permit surrogacy 13 ; however, eleven accord gestational surrogacy legal certainty while leaving traditional surrogacy in a legal limbo. ${ }^{14}$ Only four states that permit surrogacy, afford both traditional surrogacy and gestational surrogacy the same level of legal certainty. ${ }^{15}$ Unsurprisingly, gestational surrogacy has become more common than traditional surrogacy. Fertility practitioners prefer gestational surrogacy partly because of the enhanced legal certainty it offers all participants in the surrogacy arrangement. They also choose it because they believe that a gestational surrogate who is not genetically related, is less likely to change her mind and refuse to deliver the baby to the intended parents. ${ }^{16}$

The legal and medical preference in the United States for gestational surrogacy, which is highly dependent on donor eggs, raises concern that prohibitions on gamete donor anonymity could have detrimental ramifications for the practice of surrogacy. Prohibitions on gamete donor anonymity played a role in creating donor shortages in jurisdictions that adopted them. Some potential donors concerned about future contact with their conceived genetic

12 See infra text accompanying notes 22-23.

13 These states are: Arkansas, California, Florida, Illinois, Louisiana, Massachusetts, Nevada, New Hampshire, New Jersey, North Dakota, Ohio, Texas, Utah, Virginia and Washington. See infra Part $\operatorname{IV}(\mathrm{A})$.

14 These states are: These states are: California, Florida, Illinois, Louisiana, Massachusetts, Nevada, New Jersey, North Dakota, Ohio, Texas and Utah. See infra text and accompanying footnotes 86-89.

15 See infra Part III(a).

16 See infra Part III(b). 
offspring decided not to donate their gametes. Adoption of these prohibitions in the United States could contribute to creating donor gamete shortages and destabilize the practice of surrogacy in two ways. First, a scarcity in donor eggs could force a return to traditional surrogacy (in which the surrogate provides the eggs and not a third party) with the accompanying legal uncertainty. Second, the legal uncertainty enveloping traditional surrogacy could deter those in need of the services of a surrogate from seeking it altogether, resulting in a contraction of the practice of surrogacy in the United States. Although social attitudes toward surrogacy may change as the twenty-first century progresses, the potential ramifications from an abrupt change to an open identity system point to the need to act with caution when considering this change. ${ }^{17}$

Part I of this article provides a brief introduction to the practice of surrogacy. Part II discusses the impact of prohibitions on gamete donor anonymity on the supplies of donor gametes in three jurisdictions: Victoria (Australia), the United Kingdom and Sweden. Part III examines the legal and practitioner preference for gestational surrogacy over traditional surrogacy in the United States. Part IV discusses the potential destabilization of the practice of surrogacy in the United States should prohibitions on gamete donor anonymity become common.

\section{The Practice of SURRogacy}

The practice of surrogacy is comprised of two types of surrogacy. The first is traditional surrogacy, in which the surrogate is inseminated with sperm from the intended father or with donor sperm. In this type of surrogacy, the surrogate's eggs are used to conceive the baby and she is his genetic mother. ${ }^{18}$ The second type is gestational surrogacy, in which the surrogate carries a baby conceived through IVF with the sperm and egg of the intended parents or donors. In this type of surrogacy the surrogate's eggs are

17 See infra Part V.

18 Ciccarelli \& Beckman, supra note 10; AMERICAN SOCIETY FOR REPRODUCTIVE MEDICINE, supra note 10 , at 3. 
not used, and, therefore, she is not the genetic mother of the conceived baby. ${ }^{19}$

The full scope of the practice of surrogacy in the United States is unknown. There is no data available on traditional surrogacy, which is conducted via artificial insemination, a simple procedure that can be even done at home without the involvement of a doctor. ${ }^{20}$ Information about surrogacy is limited because the parties involved "have no incentive to report their numbers given the ethical debate and fear of regulatory action." 21 Two organizations collect information about gestational surrogacy: The Society of Assisted Reproductive Technologies (SART) and the Center for Disease Control and Prevention (CDC). ${ }^{22}$ However, that data lags behind, does not encompass all fertility clinics, is only partly nationally aggregated, and is not completely available to the public.

The Council of Responsible Genetics released, in 2010, a report titled Surrogacy in America, which contains the most comprehensive analysis of the data available from the CDC and SART. ${ }^{23}$ Although the report only analyzes data through 2007-2008, it gives a glimpse of the gestational surrogacy market. The report shows that the market for gestational surrogacy is growing. It reveals that from 2004 to 2008 the number of IVF cycles used for gestational surrogacy grew by $60 \%$, the number of births by gestational surrogates grew by $53 \%$ and the number of babies born to gestational surrogates grew by $89 \% .^{24}$ The report's analysis of the data suggests a high reliance on donor eggs. It

19 AMERICAN SOCIETY FOR REPRODUCTIVE MEDICINE, supra note 10 , at $13-14$.

20 Council for Responsible Genetics, Surrogacy in America, 6-7, 26 (2010), http://www.councilforresponsiblegenetics.org/pagedocuments/ kaevej0a1m.pdf.

$21 \quad I d$. at 5.

22 Id. at 4.

23 Id.

24 See id. at 3. Yet, even these numbers are incomplete because they do not include all fertility clinics in the United States and cover only completed IVF cycles, excluding incomplete ones. Id. at 8 . Therefore, these numbers cannot report how many women serve as gestational surrogates. Id. 
assesses that in 2007, medical practitioners performed 1,293 IVF cycles involving gestational surrogates. ${ }^{25}$ It also reports that 733 non-donor IVF cycles involving gestational cycles were conducted that year. ${ }^{26}$ Thus, 560 cycles, $46 \%$ of the total number of IVF cycles, were conducted using donor eggs. This figure is of particular importance because cycles using donor eggs, which are typically eggs from younger women, are more likely to result in a pregnancy and live birth. Thus, the percentage of gestational surrogate babies born through cycles using donor eggs is likely much higher than $46 \%$ of the total number of babies born through IVF cycles involving surrogates.

\section{The ImPaCt of Prohibitions on Gamete DonoR ANONYMITY ON GAMETE SUPPLIES}

Prohibiting gamete donor anonymity is a growing global trend. In jurisdictions prohibiting anonymity, egg and sperm donors are not anonymous. Instead, typically, when the child reaches the age of eighteen he can find out the identity of the egg or sperm donor - his genetic parent. ${ }^{27}$ The main goal driving the movement toward an open identity system are beliefs that children need to develop their own identity, and that possession of information regarding their genetic origins is crucial for that purpose. ${ }^{28}$

Prohibitions on gamete donor anonymity are currently in place in eleven jurisdictions. These jurisdictions include:

25 See id. at 8-9 (reporting CDC data). SART data for 2008 is significantly higher, reporting 2,502 gestational surrogate IVF cycles, 987 gestational births and 1,395 born babies. The difference is due to the fact that 53 of 483 fertility clinics do not report to CDC but do report to SART. At the same time, not all IVF clinics are members of SART, therefore, it is likely that both data-sets are under-inclusive. Id. at 12 .

26 Id. at 9.

27 See, e.g., The Infertility Treatment Act, 1995 (Vic) s 70 (Austl.) (Victorian law permitting donor conceived children to receive information about the donor once they reach the age of eighteen); Human Fertilisation \& Embryology Authority (Disclosure of Donor Information), Regulations 2004, S.I. 2004/1511, art. 2, ף 2-4 (U.K.) (United Kingdom law permitting donor conceived children to receive information about the donor once they reach the age of eighteen).

28 See TEST TUBE FAMILIES, supra note 3, at 114-129, 215-237. 
Sweden, Austria, Switzerland, the Netherlands, Norway, the United Kingdom, New Zealand, Finland, and the Australian states of Victoria, Western Australia, and New South Wales. ${ }^{29}$ In addition, a prohibition on gamete donor anonymity is presently under judicial review in Canada, following a court's decision prohibiting anonymity. ${ }^{30}$

U.S. law does not prohibit anonymous gamete donation. ${ }^{31}$ Yet, a growing movement of commentators and advocates is pursuing a shift to a regime that prohibits gamete donor anonymity. ${ }^{32}$ Moreover, in 2011, Washington State was the first state in the United States to adopt a statute that makes a prohibition on anonymity the default option the donor has to reveal her identity, unless she opts out. Yet, even if a donor opts out, the donor's medical records will remain available to the conceived offspring. ${ }^{33}$

Prohibitions on gamete donor anonymity impact a broad host of interests. Commentators have been concerned with the best interests of the children. ${ }^{34}$ Specifically, advocates of these prohibitions emphasize the importance of allowing donor conceived children to develop their identities, to access their family medical history and to avoid accidental incest with another offspring of the donor. ${ }^{35}$ Those opposed to prohibitions on anonymity discussed the privacy and procreative interests of the intended parents, who may not want their donor-conceived child to know he or she is not

29 Disclosure of Donor Identity, supra note 1, at 174-76.

30 See Pratten v. British Columbia (Att'y Gen.), 2011 BCSC 656, 9 215 (Can.).

31 TEst TUBE FAMILIES, supra note 3 , at 115.

32 See generally Id. at 114-29, 215-37; Necessary Subjects, supra note 4; Dennison, supra note 4, at 3; Shanley, supra note 4. But see Byrn \& Ireland, supra note 4 (pointing out that banning anonymity poses constitutional issues).

33 See WASH. REV. CODE $§ 26.26 .750$ (2012).

34 See generally Best Interests, supra note 7, at 461-65; Response, supra note 7; Shanley, supra note 4 , at 268-70.

35 For discussions of the importance of developing the child's identity, see TEST TUBE FAMILIES, supra note 3, at 114-129; Benward et al., supra note 7, at 232-34; Shanley, supra note 4, at 268-70. For a discussion of health concerns and the risk of incest, see, e.g., Dennison, supra note 4 , at $14-16$. 
their genetic child. ${ }^{36}$ Finally, commentators raised concerns regarding the impact on the privacy interests of the donors, who may not desire contact with the conceived child and the potential impact on donors' willingness to donate in an open identity system. ${ }^{37}$ Yet, in this Article I focus on only one aspect of the debate - the impact on gamete donor supplies - in order to examine the potential repercussions for a subset of fertility patients: those needing both donor egg and a surrogate in order to have a child.

In a study I published in 2010 , I examined the impact of prohibitions on gamete donor anonymity on gamete donor supplies. ${ }^{38}$ I studied the data available from three representative jurisdictions that prohibit anonymity: Sweden, the Australian state of Victoria and the United Kingdom. ${ }^{39}$ My study showed that, despite not always

36 See, e.g., Turkmendag, Dingwall \& Murphy, supra note 7, at 292 (emphasizing the neglect of the interests of the parents under the new U.K. policy); Byrn \& Ireland, supra note 4, at 5-15 (examining the impact of a prohibition on donor gamete anonymity on the intended parents constitutional right to procreate); Julie L. Sauer, Comment: Competing Interests and Gamete Donation: The Case for Anonymity, 39 SETON HALL L. REV. 919, 945-47 (2009) (arguing that the intended parents interests should be considered when examining prohibitions on gamete donor anonymity).

37 See, e.g., Bernstein, Regulating Reproductive Technologies, supra note 7 . at $1205-1218$ (examining the impact of prohibitions on gamete donor anonymity on gamete supplies in Victoria, Sweden and the United Kingdom); Cohen \& Coan, supra note 7, (examining the effect of prohibitions on anonymity on compensation for gamete donations); Sauer, supra note 36, at 943-45 (arguing that the donors privacy interests should be considered when examining prohibitions on gamete donor anonymity).

38 See generally Bernstein, supra note 7.

39 Id. at 1190. "I selected Sweden and Victoria because they are the first jurisdictions in which donor anonymity was prohibited. Therefore, donor-conceived children have reached or are reaching the age at which they can demand to know the donor's identity. Additionally, in these jurisdictions there is relatively more data than in other jurisdictions on the effects on the number of gamete donors. I selected the United Kingdom as a representative of a jurisdiction in which anonymity was recently prohibited. The prohibition on anonymity in the United Kingdom is currently in the midst of a heated debate and, therefore, the effects of this shift are well-documented and quantified. I should add that although I did not provide detailed information on the data in the 
consistent data, an overall picture of dire shortages in donor gametes. ${ }^{40}$

The study first examined Sweden, which in 1985 was the first jurisdiction to pass a law that allowed a child, conceived with donor sperm, to find out the identity of the donor. ${ }^{41}$ The study found that although early reports showed a decrease in the number of gamete donors based on the number of new donors per year, a 1995 article relying on data up to 1993 , found a subsequent increase. ${ }^{42}$ Based on the 1995 article, commentators believed that the prohibition on donor anonymity caused only an initial decline in gamete donor supplies. ${ }^{43}$ Yet, further investigation revealed that no one has conducted an additional study in Sweden since the mid-1990s and also that the Swedish authorities do not publish the relevant data ${ }^{44}$ But, indirect data regarding the number of donor inseminations and media reports of donor sperm shortages and long wait-lists indicated an ensuing scarcity in donor supplies. 45

Secondly, the study examined, Victoria, an Australian state, which was one of the first jurisdictions to prohibit gamete donor anonymity. 46 Victoria instated an open

other jurisdictions in which anonymity was prohibited, the overall situation of gamete shortage and long wait-lists in these jurisdictions does not appear to differ from the situation in Victoria, Sweden, and the United Kingdom." Id. at 1207, n. 101.

$40 \quad I d$. at 1219.

41 Id. at 1207; Erling Ekerhovd, Anders Faurskov \& Charlotte Werner, Swedish Sperm Donors Are Driven by Altruism, but Shortage of Sperm Donors Leads to Reproductive Travelling, 113 UPSALA J. MED. SCI. 305, 305 (2008).

42 Bernstein, supra note 7, at 1207-08.

$43 \quad$ E.g., Ken Daniels \& Othon Lalos, The Swedish Insemination Act and the Availability of Donors, 10 HUM. REPROD. 1871, 1872-73 (1995).

44 Bernstein, supra note 7 , at 1208.

$45 \quad I d$. (noting that Sweden allows compensation of donor gametes; therefore, a prohibition on compensation has not played a role in creating shortages); see also $8 \mathrm{ch} .6 \S$ LAG OM GENETISK INTEGRITET [The Genetic Integrity Act], (Svensk författningssamling [SFS] 2006:351) (Swed.) (Since 2006, Sweden has begun prohibiting trading in eggs and sperm for profit, but gamete owners who donate their gametes are still compensated.).

46 Bernstein, supra note 7, at 1209. 
identity regime in two stages. First, in 1985, it enacted the Infertility (Medical Procedures) Act 1984 ("Infertility Act of 1984 "), which went into effect in 1988, and created a donor register. ${ }^{47}$ However, under the Infertility Act of 1984, no information could be released without the donor's consent. ${ }^{48}$ In 1995, the Victorian legislature enacted the Infertility Act of 1995, which came into effect in 1998, and allowed donor conceived children to access information about donors once they reach the age of eighteen. ${ }^{49}$ The study examined officially released figures of the number of new donors per year and showed that although the number of sperm donors fluctuated between individual years, the figures demonstrated a gradual decline in the number of new donors, corresponding with the enactment and enforcement of the two acts. ${ }^{50}$ The study noted that while other factors, including the introduction of more effective reproductive technologies, such as IVF and intracytoplasmic sperm injection ("ICSI") could have decreased the need for sperm donors, the media continues to report shortages in sperm supply. ${ }^{51}$

47 The Infertility (Medical Procedures) Act, 1984 (Vic) s 19 (Austl.).

48 Id.

49 The Infertility Treatment Act, 1995 (Vic) s 70 (Austl.). For a description of the legislative history in Victoria, see Lyria Bennett Moses, Understanding Legal Responses to Technological Change: The Example of In Vitro Fertilization, 6 MinN. J.L. SCI. \& TECH. 505, 555-59 (2005). In addition, the National Health and Medical Research Council in Australia publishes ethical guidelines requiring use of gametes from donors who agree to release their identifying information. These guidelines are not mandatory. See also AUSTL. NAT'L HEALTH \& MED. RESEARCH COUNCIL, ETHICAL GUIDELINES ON THE USE OF ASSISTED REPRODUCTIVE TECHNOLOGY IN ClINICAL PRACTICE AND RESEARCH $§ 6.1$, at 25-26 (2007), available at http://www.nhmrc.gov.au/files_nhmrc/file/ publications/synopses/e78.pdf.

50 Bernstein, supra note 7 , at 1209-10.

51 Id. at 1210-11. The study acknowledged that another factor that contributed to the decrease in gamete donors is the federal Australian prohibition on compensation. However, it notes that this prohibition was only enacted in 2006 and went into effect in 2007 and, therefore, does not account for the earlier gamete shortage. See The Prohibition of Human Cloning for Reproduction and the Regulation of Human Embryo Research Amendment Act 2006 (Cth) s 21 (Austl.) (prohibiting donor compensation in excess of reasonable expenses). The relevant 
Finally, the study examined the impact on gamete supplies in the United Kingdom, where a law prohibiting donor gamete anonymity came into effect in $2006 .^{52}$ The study assessed the official data released and concluded that it portrayed a mixed picture. ${ }^{53}$ The data did not reveal more than an initial decline in the yearly number of newly registered donors. ${ }^{54}$ However, the study noted that some reports point out that the numbers of registered donors is misleading because of the increase in known donors friends or relative who usually donate for only one person's exclusive use. ${ }^{55}$ At the same time, other parts of the data raised concern. The study's examination of the data revealed a decline in the number of newly registered egg share donors (women undergoing IVF to have their own child and donating excess eggs). ${ }^{56}$ In addition, examining indirect data, it noted a decline in the number of IVF treatment cycles with donated eggs or sperm. ${ }^{57}$ The study concluded that although the data from the United Kingdom is mixed, it warrants concern regarding the impact that the prohibition on gamete donor anonymity had on the availability of the gamete supplies.58 Moreover, these

prohibition in the state of Victoria was enacted in 2008 and came into effect on January 1, 2010. The Prohibition of Human Cloning for Reproduction Act 2008 (Cth) s 17 (Austl.).

52 Human Fertilisation \& Embryology Authority (Disclosure of Donor Information), Regulations 2004, S.I. 2004/1511, art 2 . I 1 (U.K.).

53 Bernstein, supra note 7, at 1211.

$54 \quad I d$.

55 Id. at $1211-12$.

$56 \quad$ Id. at 1212 .

57 Id. Although the number of treatment cycles began declining since 2001, suggesting that other factors such as utilization of more effective reproductive technologies played a role here.

58 Id. Since this Article focuses on the potential impact of prohibitions on anonymity on the supply of eggs for surrogacy, the United Kingdom data, which includes data on eggs is particularly important. My study was conducted a relatively short time after the prohibition on anonymity came into effect in the United Kingdom. Unfortunately, the current data does not provide a clearer picture. As before, the overall number of newly registered egg donors is generally not lower than before the law came into effect. New Donor Registrations, HUMAN FERTILIZATION AND EMBRYOLOGY AUTH., http:// www.hfea.gov.uk/3411.html (last visited Feb. 2, 2013). However, the 
concerns are exacerbated in light of media and commentator reports of long wait lists for donor gametes. ${ }^{59}$ However, the study noted that although it appears that the prohibition on anonymity played a role in decreasing gamete supplies, other factors such as the prohibition on compensation for gamete donors, likely also played a significant part in enhancing the shortage. 60

The study suggested that potential donors' concerns of future contact by the conceived offspring influenced their decision-making. ${ }^{61}$ In light of the study's findings in other jurisdictions, the adoption of prohibitions on anonymity in the United States could play a role in creating shortages in gamete supplies. As was the case abroad, potential donors in the United States may be deterred from donating, fearing future contact by the conceived offspring. Since prohibitions on gamete donor anonymity are likely to be adopted on a state-by-state basis and not by the federal government, the effect on gamete supplies would depend on the number of states that would adopt these prohibitions.

At the same time, advocates of an open identity system are likely to point to the fact that, unlike some jurisdictions that prohibit anonymity, compensation for gamete donors is not prohibited in the United States. And importantly, Glenn Cohen and Travis Coan have shown that sperm donors are

Human Fertilization Embryology Authority no longer releases the data of newly registered egg share donors per year. Egg Share Donors and Non-Patient Egg Donors, Human FERTILIZATION AND Embryology AUTH., http://www.hfea.gov.uk/3412.html (last visited Feb. 2, 2013). It only publishes the overall number of yearly egg share donors. Egg Share Donors and Non-Patient Egg Donors, HUMAN FERTILIZATION AND EMBRYOLOGY AUTH., http://www.hfea.gov.uk/3412.html (last visited Feb. $2,2013)$. Therefore, it is impossible to confirm whether the levels of newly registered egg share donors have risen or declined since I have conducted my study. At the same time, the number of IVF treatment cycles with donated eggs are still well below the number of cycles conducted before the law came into effect. Donor Conception Patient and Treatment, HUMAN FERTILIZATION AND EMBRYOLOGY AUTH., http:// www.hfea.gov.uk/donor-conception-treatments.html (last visited Feb. 2, 2013).

59 Bernstein, supra note 7, at 1212-13.

$60 \quad I d$. at 1213.

$61 \quad I d$. at 1215. 
willing to reveal their identity for a higher compensation. ${ }^{62}$ This suggests that prohibitions on donor gamete anonymity may not create shortages in the United States, but instead raise prices for sperm and egg. It is possible that prohibitions on compensation combined with prohibitions on gamete donor anonymity played a role in creating gamete donor shortages in other jurisdictions. Nevertheless, in Sweden and Victoria, prohibitions on anonymity affected donor supplies even in the absence of prohibitions on compensation. ${ }^{63}$ Furthermore, Cohen and Coan's study has two important limitations. First, the authors acknowledged that the study was only a hypothetical study. ${ }^{64}$ The participants did not, in fact, donate their sperm. ${ }^{65}$ Interestingly, even in the jurisdictions in which my study observed a decline in donor gametes, hypothetical studies did not predict this decline. ${ }^{66}$ Secondly, Cohen and Coan's study shows that prohibitions on anonymity would cause a price increase of $73 \%$ in the price of sperm. ${ }^{67}$ Sperm is relatively cheap costing the average price of $\$ 300$ per vial, ${ }^{68}$ while eggs are more expensive. The average price recipients

\footnotetext{
62 Glenn Cohen \& Travis G. Coan, supra note 7, at 4.

63 Bernstein, supra note 7, at 1209, 1211.

64 Glenn Cohen \& Travis G. Coan, supra note 7, at 24.

65 Id. at 9.

66 See, e.g., K. Daniels et al., Short Communication: Previous
} Semen Donors and Their Views Regarding the Sharing of Information with Offspring, 20 HUM. REPROD. 1670, 1671, 1673 (2005); K.R. Daniels, Semen Donors: Their Motivations and Attitudes to their offspring, 7 J.REPROD. \& INFANT PSYCH. 121 (1989), see also Julian N. Robinson \& Robert G. Forman et al., Attitudes of Donors and Recipients to Gamete Donation, 6 Hum. REPROD. 307, 307-308 (1991) (showing that while existing donors are not deterred by loss of anonymity, potential donors are); but see, Rachel Cook \& Susan Golombok, A Survey of Semen Donation: Phase II - The View of the Donors, 10 Hum. REPROD. 951, 954 (1994) (finding that two-thirds of donors stated that they would not donate if their identifying information would be given to the conceived child).

67 Cohen \& Coan, supra note 7, at 23.

68 See DeBorah L. SPAR, The Baby Business: How Money, SCience AND Politics DRIVe the Commerce of Conception, at xvi (2006). 
pay an egg donor is $\$ 4,500.69$ Thus, a similar increase in the price for eggs could result in a significant contraction of the market for eggs because few buyers will be able to afford the purchase. Consequently, even in the absence of prohibitions on compensation, prohibitions on anonymity in the United States carry the risk of depleting gamete supplies.

In addition, the data provided focuses mostly (excluding the United Kingdom) on sperm donors. Some commentators believe that egg donors may be less affected by the removal of anonymity than sperm donors because they are more interested in the outcome of their donation. ${ }^{70}$ While many studies examined the attitudes of sperm donors and egg donors toward anonymity and the conceived offspring, the two were not compared in a single study. ${ }^{71}$ Interestingly, one study comparing the attitudes of egg and sperm donors toward the conceived children, although not focusing directly on anonymity, showed that sperm donors felt a paternity relationship to the conceived children, while egg donors distanced themselves from the conceived children as not having a family relationship to them. ${ }^{72}$ Thus, in the absence of conclusive data comparing sperm and egg donors' attitudes toward the removal of anonymity, it is impossible to predict whether removal of anonymity in the United States will have disparate impact on egg donors.

Finally, social attitudes toward anonymity may change as the twenty-first century progresses. ${ }^{73}$ One might argue

69 See Id. And this price is, in fact, much higher because the recipient also has to pay for all the donor's retrieval costs. These costs can amount to an additional $\$ 10,000$ per retrieval cycle. See ELLEN SARASOHN GLAZER \& EvElina WEIDMAN STERLING, HAVING YOUR BABY THROUGH EGG DONATION, 211-212 (2011).

70 See, e.g., Eric Blyth \& Lucy Frith, The UK's Gamete Donor Crisis - A Critical Analysis, 28 CRITICAL SoC. POLICY, 74, 83-84 (2008).

71 See $i d$. at 83 , for acknowledgement that variation in study design, chronology and cultural contexts in which different studies have been undertaken need to be taken into account when comparing and contrasting the views of egg and sperm donors.

72 See Rene Almeling, Sex Cells: The Medical Market for EGGS AND SPERM 143-153 (2011).

73 As was the case with the social acceptance accompanying the shift from closed to open adoption records. See Ellen Waldman, What Do We Tell the Children? 35 CAP. U. L. REV. 517, 520-532 (2006). 
that a society that is open to the idea of identified donors is more likely to produce a larger pool of donors who would be willing to donate despite the absence of anonymity. However, current evidence from jurisdictions like Sweden and Victoria, where prohibitions on donor anonymity have been in force for over two decades, does not indicate such a shift. Instead, it appears that prohibitions on anonymity still play a role in creating shortages in gamete donations in these jurisdictions. And, although attitudes may change globally and domestically in coming years, without evidence of a shift of attitudes, concerns regarding the impact of gamete supplies remain.

\section{A PREFERENCE FOR GESTATIONAL SURROGACY}

The legal regime governing surrogacy in the United States differs from the corresponding regime in most jurisdictions that prohibit donor anonymity. This Part will show that most states that permit surrogacy recognize or provide legal certainty only to gestational surrogacy, which is highly dependent on donor eggs. Furthermore, U.S. medical practitioners endorse a preference for gestational surrogacy, believing it is a safer practice both legally and psychologically.

\section{A. Legal Preference}

Most jurisdictions that prohibit gamete donor anonymity do not distinguish between traditional and gestational surrogacy. Sweden, ${ }^{74}$ Norway, ${ }^{75}$ Switzerland, ${ }^{76}$ Austria, ${ }^{77}$

74 Göran Hermerén, Surrogatmoderskap: Varför - och varför inte? LÄKARTIDNINGEN January 18, 2011, at 68-69 (Swed.) available at http:// www.lakartidningen.se/07engine.php?articleId=15828 (explaining that Sweden prohibits surrogacy).

75 NORWEGIAN MINISTRY OF FOREIGN AFFAIRS, Assistance TO NORWEGIANS ABROAD (WhITE PAPER) 33 (2011) (Nor.), available at http://www.regjeringen.no/pages/38027779/PDFS/STM20102011001200 0EN_PDFS.pdf (noting under Norwegian law the woman who has given birth to the child is regarded as the mother of the child and that egg donation is prohibited in Norway, which means that gestational surrogacy using a donor egg is illegal); see also SUSAN MARKENS, 
Finland, ${ }^{78}$ and the Netherlands ${ }^{79}$ prohibit or generally refuse to enforce any surrogacy arrangement. The United Kingdom, ${ }^{80}$ New South Wales ${ }^{81}$ and New Zealand ${ }^{82}$ permit

Surrogate Motherhood and the Politics of Reproduction 24-25 (2004).

76 Schweizkris'Hes Zivilgesetzbuch [ZGB], Code CIVIL [CC], Codice Civile [CC] [CIvil CoDe] Dec. 18, 1998, SR 810.11, RS 810.11, art. 2(a)(k) (Switz.) (defining a surrogate mother as a woman who becomes pregnant by either artificial insemination or IVF); SCHWEIZERISCHES ZIVILGESETZBUCH [ZGB], CODE CIVIL [CC], CODICE CIVILE [CC] [Civil Code] Dec. 18, 1998, SR 810.11, RS 810.11, art. 4 (Switz.) (prohibiting surrogate motherhood). See also Daniel Gruenbaum, Foreign Surrogate Motherhood: mater semper certa erat, 60 AM. J. COMP. L. 475, 480 n. 35 (2012).

77 Allgemeines BÜrgerliches GesetzBuCh [ABGB] [Civil Code] BUNDESGESETZBLATT [BGBL] No. 118/2002, §137b (Austria) (stating that the birth mother is always the legal mother). See also Markens, supra note 75 , at $24-25$.

782 ch. 8(6) §, Act on Assisted Fertility Treatments (1237/2006) (Fin.) (unofficial translation), available at http://www.finlex.fi/fi/laki/ kaannokset/2006/en20061237.pdf (stating that Finnish law prohibits assisted fertility treatment if there is reason to believe that the child will be given up for adoption, thus, effectively prohibiting surrogacy).

79 In the Netherlands, the woman who gives birth to the child is the legal mother. The law contains no procedure for transferring rights from the surrogates to the intended parents. Surrogacy agreements are considered against good morals and are therefore null and void. Yet, courts may reduce hurdles to grant the child to the intended parents where the intended parents are both the genetic parents. Machteld Vonk, The Role of Formalised and Non-Formalised Intentions in Legal Parent-Child Relationships in Dutch Law, 4 UltRecht L.REV. 117, 123124, 128-131 (2008) (Neth.).

80 Hugh V. McLachlan and J. Kim Swales, Commercial Surrogate Motherhood and the Alleged Commodification of Children: A Defense of Legally Enforceable Contracts, 72 LAW \&. PROBS., Summer 2009, at 9293; Pip Trowse, Surrogacy - Is It Harder to Relinquish Genes, 18 J. L. \& MED. 614, 632-33, 643-45 (2011) (Austl.).

81 See generally Surrogacy Act 2010 No 102 (NSW) (Austl.).

82 Section 14 of the Human Assisted Reproductive Technology Act 2004 (N.Z.) (stating that surrogacy is not illegal but not enforceable); Section 5 of the Human Assisted Reproductive Technology Act 2004 (N.Z.) (defining surrogacy as an arrangement under which a woman agrees to become pregnant for the purpose of surrendering custody of a child born as a result of the pregnancy); ADVISORY COMMITTEE ON Assisted REPRODUCTIVE TECHNOLOGY, GUIDELINES ON SURROGACY ARRANGEMENTS INVOLVING PROVIDERS OF FERTILITY SERVICES (2007) (N.Z.) (containing guidelines for providers to approve surrogacy). Yet, 
altruistic surrogacy arrangements but do not distinguish between gestational and traditional surrogacy. There are only two jurisdictions, the Australian states of Victoria and Western Australia, that prohibit gamete donor anonymity and distinguish between gestational and traditional surrogacy. 83

The legal landscape in the United States is different. This section will show that among the states that permit surrogacy, most provide legal certainty only to gestational surrogacy and not to traditional surrogacy. Consequently, only those engaged in gestational surrogacy can be assured that the surrogacy agreement will be enforced, and parental rights will be given to the intended parents and not to the surrogate and her husband. Traditional surrogacy arrangements do not benefit from the assurance of legal certainty, and stand the risk that parental rights will be given to the surrogate and her husband.

Federal law does not regulate either gestational or traditional surrogacy. 84 Some states, whether through statute or judicial opinions, have reacted to regulate surrogacy, but will vary significantly across jurisdictions. Some states prohibit surrogacy, some states are silent and their laws give no indication as to whether surrogacy is permitted, while other states allow it but usually with some restrictions. ${ }^{85}$ When a state permits surrogacy, even with

the surrogate and her husband are the legal parents of the born child and the intended parents need to adopt the child. New Zealand Law Commission, Surrogacy Status of the Children of a Surrogacy Arrangement, NZLII.ORG (May 24, 2004), http://www.nzlii.org/nz/ other/nzlc/pp/PP54/.

83 In Victoria, the Patient Review can only approve a surrogacy arrangement if it is satisfied the surrogate's eggs were not used, as opposed to Western Australia where the courts can dispense with the requirements that the surrogate consent to the parentage order and receive counseling and legal advice if she is not the genetic mother. Parentage Act 2004 (ACT) s 24 (Austl.); Surrogacy Act 2008 (WA) s 21 (Austl.); Trowse, supra note 80, at 634-35.

84 Spar, supra note 68 , at 84.

85 See Paul G. Arshagouni, Be Fruitful and Multiply by Other Means, If Necessary: The Time Has Come to Recognize and Enforce Gestational Surrogacy Agreements, 61 DEPAUL L. REV. 799, 805-08 (2012); Radhika Rao, Surrogacy Law in the United States: The Outcome 
conditions, the result is that the surrogacy agreement is enforced and the intended parents (not the surrogate) have parental rights.

Commentators have noted a growing preference among states for gestational surrogacy. ${ }^{86} \mathrm{My}$ review of state law has confirmed this and specifically has revealed that of fifteen states that permit surrogacy 87 only four states, namely: Arkansas, ${ }^{88}$ New Hampshire, ${ }^{89}$ Virginia, ${ }^{90}$ and

of Ambivalence, in SURROGATE MOTHERHOOD: INTERNATIONAL Perspectives 23, 23 (Rachel Cook \& Shelley Day Sclater eds., Hart 2003).

86 See, e.g., Weldon E. Havins, Reproductive Surrogacy at the Millennium: Proposed Model Legislation Regulating "Non-Traditional" Gestational Surrogacy Contracts, 31 MCGEORGE L. REV. 673, 674 (2000) (arguing for the need for legislation that would recognize the important differences between gestational and traditional surrogacy); Elizabeth Scott, Making Markets in Forbidden Exchange: Surrogacy and the Politics of Commodification, 72 LAW \& CONTEMP. PROBS. 109, 122-23 (2009) (describing a judicial and statutory trend toward enforcing gestational surrogacy agreements while leaving traditional arrangements in a legal void).

87 This list does not include states that are generally silent on whether surrogacy is legal or states in which there is no consensus regarding whether surrogacy is, in fact, permitted and whether the intended parents' rights would be enforced against the surrogate. Specifically, Tennessee is not included, which is sometimes listed as a state that allows surrogacy, because its statute is contradictory and there is no case law adjudicating surrogacy. See TENN. CODE. ANN. § 361-102(48) (2012) (providing that in both traditional and gestational surrogacy the surrogate relinquishes rights to the intended parents, but also states that this provision will not be construed "to expressly authorize the surrogate birth process in Tennessee unless otherwise approved by the courts or the general assembly").

88 The language of the statute in Arkansas appears to expressly permit only traditional surrogacy. See ARK. CODE ANN. § 9-10-201 (2012) (focusing on surrogacy through artificial insemination). Yet, the focus on artificial insemination is likely the result of the technology available at the time the statute was enacted. Arkansas law has been widely interpreted to recognize both traditional and gestational surrogacy. See Katherine Drabiak, Carole Wegner, Ethics, Law and Commercial Surrogacy: A Call for Uniformity, 35 J. L. MED. \& ETHICS 300, 302 (2007); Darra L. Hofman, Mama's Baby, Daddy's Maybe: A State-By-State Survey of Surrogacy Laws and Their Disparate Gender Impact, 35 WM. MitchelL L. REv. 449, 461 (2009); Council for Responsible Genetics, supra note 20, at 29. 
Washington ${ }^{91}$ allow both traditional and gestational surrogacy. The remaining eleven states allow only gestational surrogacy or show a clear preference for it by granting it increased legal certainty.

One approach expressly distinguishes between the two forms of surrogacy, recognizing gestational surrogacy while stating that traditional surrogacy will not be enforced. In California, case law indicates that genetic parents will first be assigned parental rights, which make a traditional surrogate the legal mother. However, when the surrogate is a gestational surrogate, with no genetic link, the intended parents, whether they are genetically related or not, are assigned parental rights. ${ }^{92}$ Furthermore, in 2012, California

89 N.H. REV. STAT. ANN. § 168-B:1 (2012) (defining surrogacy as "any arrangement by which a woman agrees to be impregnated using either the intended father's sperm, the intended mother's egg, or their pre-embryo with the intent that the intended parents are to become the parents of the resulting child after the child's birth."); N.H. REV. STAT. ANN. § 168-B:1 (2012) (providing that surrogacy agreements can be lawful). It is not clear though that New Hampshire recognizes surrogacy agreements in which a donor egg was used. See N.H. REV. STAT. ANN. § 168-B:17 (2012) (stating that the intended mother or surrogate shall provide the ovum). See also Arshagouni, supra note 85, at 807, n.46 (2012).

90 VA. CODE ANN. $§ 20-156$ (2012) (providing that a surrogacy agreement involves a surrogate who agrees to be impregnated through assisted reproduction, which includes both IVF and artificial insemination); VA. CODE ANN. § 20-159 (2012) (provides for parental rights for the intended parents under a surrogacy agreement).

91 WASH REV. CODE $\S 26.26 .210$ (2012) (defining surrogate parentage contracts as encompassing both gestational and traditional surrogacy); WASH REV. CODE $\S$ 26.26.230 (2012) (forbidding only compensated surrogacy contracts); WASH REV. CODE $§$ 26.26.101 (2012) (providing that the woman giving birth is the mother except under a valid surrogacy agreement); WASH REV. CODE $§ 26.26 .260$ (2012); WASH REV. CODE $\S 26.09 .187$ (2012) (providing a multi-prong factor list to resolve custody disputes between the surrogate and the intended parents). In addition, an attorney general opinion from 1989 states that a surrogate parenting agreement is not enforceable against a surrogate mother who withdraws her consent to relinquish her child before court approval of the consent. AGO 1989 No. 4 (Wash.), 1989 Wash. AG LEXIS 41.

92 Johnson v. Calvert, 851 P.2d 776, 782 (Cal. 1993) (finding that when the surrogate who gave birth is not the genetic mother, the woman who is genetically related to the child and intended to have the 
adopted a statutory scheme, which confirms the courts' approach, and enforces only gestational surrogacy agreements. ${ }^{93}$ Similarly, in New Jersey and in Ohio courts have recognized gestational surrogacy agreements, while refusing to enforce traditional surrogacy agreements. ${ }^{94}$ In Illinois and North Dakota, statutes achieve a similar effect, by expressly recognizing gestational surrogacy, while refusing to grant such recognition to traditional surrogacy. ${ }^{95}$

child is the legal mother); In re Marriage of Moschetta, 30 Cal. Rptr 893, 894-95 (Cal. Ct. App. 1994) (refusing to enforce a surrogacy agreement where the surrogate was both the genetic and the birth mother); In re Marriage of Buzzanca, 72 Cal. Rptr. 2d 280, 282 (Cal. Ct. App. 1998) (holding that when the child is not genetically related to the surrogate or the intended parents, the intended parents are the legal parents).

$93 \quad$ See CAL. FAM. CODE $§ \S 7960,7962$ (Deering 2012).

94 For New Jersey law, see In re Baby M, 537 A.2d 1227, 12341235 (N.J. 1988) (refusing to enforce a traditional surrogacy agreement); A.H.W. v. G.H.B., 772 A.2d 948, 954 (N.J. Super. Ct. Ch. Div. 2000) (allowing a gestational surrogacy agreement and granting legal parental rights where the intended parents were the genetic parents); Council for Responsible Genetics, supra note 20, at 36. But see In re T.J.S. 16 A.3d 386, 388, 393-94 (N.J. Super. Ct. App. Div. 2010) cert granted 207 N.J. 228, 23 A.3d 935 (2011) (finding that where a donor egg was used in a gestational surrogacy the intended mother is not the legal mother unless the baby is adopted by her). For Ohio law, see F. v. D.B. 879 N.E.2d 740. 740-41 (Ohio 2007) (holding that a gestational surrogacy agreement prohibiting the surrogate from asserting parental rights is valid because she has no claim to legal parentage); Belsito v. Clark, 644 N.E.2d 760, 762, 767 (Ohio Misc. 2d 1994); (holding that in a gestational surrogacy arrangement the intended parents who are also the genetic parents are the legal parents); Seymour v. Stotski, 611 N.E.2d 454, 454, 458 (Ohio Ct. App. 1992) (refusing to recognize the intended mother in a traditional surrogacy agreement as the legal mother); Council for Responsible Genetics, supra note 20, at 37.

95 For Illinois law, see 750 ILl. CoMP. STAT. 47/10 (2012) (defining gestational surrogacy as an arrangement in which "the gestational surrogate has made no genetic contribution"); 750 ILL. COMP. STAT. $47 / 15$ (2012) (granting the intended parents in a gestational surrogacy arrangement the status of legal parents); 750 ILL. COMP. STAT. 47/15 (2012) (stating that "except as provided in this Act, the woman who gives birth to a child is presumed to be the mother of that child for purposes of state law."). For North Dakota law, see N.D. CENT. CODE § 14-18-05 (2012) (stating that surrogacy agreements are void and unenforceable and the child born is the child of the surrogate and her husband); N.D. CENT. CODE $§ 14-18-08$ (2012) (stating that the child 
A second approach expressly recognizes gestational surrogacy, but does not illegalize traditional surrogacy. The states exercising this approach include Nevada, ${ }^{96}$ Texas, ${ }^{97}$ and Utah. ${ }^{98}$ Consequently, gestational surrogacy is accorded legal certainty while traditional surrogacy remains in a legal limbo, which may mean that it will not be enforced or that enforcement is uncertain.

Louisiana and Massachusetts endorse a third approach. Both expressly refuse to enforce traditional surrogacy, but at the same time, do not provide an express statement authorizing the enforcement of gestational surrogacy agreements. The statutory law of the state of Louisiana expressly states that compensated traditional surrogacy is void and unenforceable, but does not address uncompensated arrangements or gestational surrogacy. ${ }^{99}$ In Massachusetts, case law creates a de facto preference for gestational surrogacy, although no court has ruled directly on the enforceability of gestational surrogacy agreements. In one instance, a court ruled that where the intended

born to a gestational surrogate is the child of the intended parents); Council for Responsible Genetics, supra note 20, at 35-36.

96 In Nevada unpaid gestational surrogacy using the gametes of the intended parents is recognized. See NEv. REv. STAT. § 126.045 (2012) (recognizing gestational surrogacy when intended parents gametes are used); Kimberly M. Surratt, Special Feature: Parenthood through Technology, 15 NEVADA LAWYER 8, 8 (2007) (describing the surrogacy arrangements that are not covered under Nevada law).

97 TEX. FAM. CODE $\S 160.755$ (West 2012) (permitting courts to validate gestational agreements); TEX. FAM. CODE $\S 160.762$ (West 2012) (stating that gestational agreements that are not validated by courts are unenforceable); TEX. FAM. CODE $§ 160.753$ (West 2012) (when a court validates the agreement the intended parents become the legal parents); TEX. FAM. CODE $§ 160.754$ (c) (West 2012) ("The gestational agreement must require that the eggs used in the assisted reproduction procedure be retrieved from an intended parent or donor. The gestational mother's eggs may not be used in an assisted reproduction procedure"). See Trowse, supra note 80 , at $626-27$ (emphasizing that under Texas law only surrogacy arrangements in which the surrogate is not genetically related to the child will be enforced).

98 UTAH CODE ANN. \$78B-15-801 (LexisNexis 2012) (allowing gestational surrogacy agreements but providing that "the gestational mother's eggs may not be used in the assisted reproduction procedure.").

99 LA. REV. STAT. ANN. § 9:2713 (2012). 
parents were the genetic parents, and the surrogate wished to relinquish her parental rights, the intended parents should be listed on the birth certificate. ${ }^{100}$ In another instance, the court refused to enforce a traditional surrogacy agreement. ${ }^{101}$ This approach, while clarifying that traditional surrogacy is illegal and inadvisable, leaves the door open to potential enforcement of gestational surrogacy.

Finally a fourth approach, endorsed by Florida recognizes both types of surrogacy but increases the legal certainty of gestational surrogacy by imposing additional hurdles on the enforcement of traditional surrogacy. Florida treats only traditional surrogacy under a pre-planned adoption agreement regime. Under this regime the surrogate has a right of rescission within 24 hours after the birth of the child. 102

\section{B. Medical Practioners' Preference}

While there is some, albeit incomplete, data regarding the practice of gestational surrogacy, there is no data on the prevalence of traditional surrogacy. Thus, no comprehensive empirical study has been conducted to determine whether gestational surrogacy or traditional surrogacy is the preferred practice in the United States. ${ }^{103}$ At the same time, some commentators 104 and medical sources note that

100 See Culliton v. Beth Isr. Deaconess Med. Ctr. 756 N.E.2d 1133, 1135, 1137-38 (Mass. 2001).

101 See R.R. v. M.H. 689 N.E.2d 790, 791,795-96,797 (Mass. 1998).

102 See FLA. STAT. $\$ \S 742.13 ; 742.15$ (2012) (recognizing gestational surrogacy); FLA. STAT. $\S 63.213$ (2012) (recognizing traditional surrogacy); FLA. STAT. $\S 63.213(2)(\mathrm{a})$ (2012) (requiring a right of rescission for pre-planned adoption agreements). See also Trowse, supra note 80 , at $627-29$.

103 One study conducted in 2000 of twenty randomly selected Californian surrogacy agencies showed that $30 \%$ offered only gestational surrogacy. Mhairi Galbraith, Hugh V.McLachlan et al., Commercial Agencies and Surrogate Motherhood: A Transaction Cost Approach, 13 HeALTH CARE ANALYSIS 11, 20-21 (2005).

104 See, e.g., Carol Sanger, Developing Markets in Baby-Making: In the Matter of Baby $M, 30$ HARV. J.L. \& GENDER 67 (2007) (stating that most surrogacy arrangements today involve gestational surrogacy); 
gestational surrogacy now dominates the practice of surrogacy. ${ }^{105}$ Specifically, the American Society for Reproductive Medicine states in its Third Party Reproduction: A Guide for Patients that "[t]raditional surrogacy arrangements often are perceived as controversial [and] . . . the utilization of a gestational surrogate ... is the more common approach conducted in the United States."106

The legal preference for gestational surrogacy, apparently, has trickled to medical circles. Infertility specialists believe that gestational surrogacy is legally safer. The American Society for Reproductive Medicine's guide for patients states that traditional surrogacy is more likely to be legally complicated, while gestational surrogacy is a, legally, lower risk procedure. ${ }^{107}$ Warnings regarding the increased legal risk are also passed on to infertility patients through Internet fertility sources. ${ }^{108}$

At the same time, practitioners' preference for gestational surrogacy stems also from concerns that the

Scott, supra note 86 , at 139 (stating that most surrogates today are not the genetic mothers of the born child). But cf., Council for Responsible Genetics, supra note 20, at 6 (stating that the cost of IVF, which is needed for gestational surrogacy, compared to the cost of artificial insemination needed for traditional surrogacy, suggests that many parents will choose traditional surrogacy).

105 See, e.g., Lauren Fertility Care, Is Traditional or Gestational Surrogacy More Common?, FERTILITY PRO REGISTRY (Jan. 25, 2010), http://www.fertilityproregistry.com/qa/is-traditional-or-gestationalsurrogacy-more-common (noting that "[v]ery few infertility practices do traditional surrogacy anymore ...").

106 American Society for Reproductive Medicine, Third Party Reproduction: A Guide for Patients, supra note 8, at 3.

107 Id.

108 See e.g., Gestational Surrogacy v. Traditional Surrogacy, HubPAGES.COM, (Dec. 7, 2010), http://megscc.hubpages.com/hub/ Gestational-Surrogacy-vs-Traditional-Surrogacy ("Traditional [sic] can be A LOT more risky with the surrogate being the actual biological mother. Legally she is the mother until she signs her rights away. There have been cases where the Traditional surrogate has changed her mind and it became a custody battle ... With Gestational Surrogacy the Surrogate is NOT related to the child and less likely to want to keep the child. And if she did try to keep the child she really does not have much ground to stand on because she is NOT the biological mother."). 
emotional attachment of the surrogate will increase the likelihood that she will change her mind and refuse to deliver the child to the intended parents. These concerns apply to both gestational and traditional surrogacy. ${ }^{109}$ However, medical professionals have emphasized that these problems are more likely to arise when the surrogate is genetically related to the child. ${ }^{110}$ A recent study reviewing case-law and empirical evidence concluded that traditional surrogates are more likely to refuse to deliver the born child to the intended parents than gestational surrogates. ${ }^{111}$ Other medical professionals, including those describing their own clinical experience, have also reported that traditional surrogates, who are carrying their genetically related child, are more likely to experience difficulty detaching from the baby than gestational surrogate who are carrying a child who is not genetically linked to them. ${ }^{112}$

109 See Vasanti Jadva, Clare Murray et al., Surrogacy: The Experiences of Surrogate Mothers, 18 HuM. REPROD. 2196, 2196 (2003) (reviewing earlier literature regarding the psychological well-being of surrogates). But see Id. at 2197, 2203 (concluding based on a study of thirty four traditional and gestational surrogates that surrogacy has been a generally positive experience for surrogates whether traditional or gestational).

110 AMERICAN SOCIETY FOR REPRODUCTIVE MEDICINE, supra note 10, at 3 (stating that "[t]raditional surrogacy arrangements often are perceived as controversial with the potential to be complicated... psychologically").

11 Trowse, supra note 80 , at 616 .

112 See generally Peter R. Brinsden, Gestational Surrogacy, 9(5) HUM. REPROD. 483, 487 (2003) (stating that "[t]he issue which causes most concern to commissioning couples is that the host may wish to retain custody of the child. This has occurred, but is very rare, particularly in gestational surrogacy arrangements where there is no genetic link to the surrogate mother."); Ciccarelli \& Beckman, supra note 10 , at $33-34$ (stating that the only study that found that a significant minority of surrogates experienced significant emotional distress when parting from the baby, $25 \%$ of the study participants, differed from other studies about the psychological effects on surrogates because, in that study, all but two of the surrogate mothers were traditional surrogates); Mary E. English, Andrea Mechanick-Braverman et al., Semantic and Science: The Distinction Between Gestational Carrier and Traditional Surrogacy Options, 1 WOMEN's HEALTH ISSUES 155,156 (1991) (reporting that potential surrogate carriers state that while they can accept carrying a child that is biologically unrelated to 


\section{Potential Ramifications of Prohibition on Gamete DONOR ANONYMITY ON THE PRACTICE OF SURROGACY}

Women with certain medical problems and gay men may require both donor eggs and a surrogate in order to have a child who is genetically related to one of the partners. ${ }^{113}$ However, prohibitions on gamete donor anonymity have played a role in creating shortages in the supplies of egg and sperm. This Part posits that should prohibitions on gamete donor anonymity become common in the United States, they could contribute to creating donor gamete shortages. Consequently, while individuals requiring donor eggs can now rely on the legal rights granted to gestational surrogacy in most of those states permitting such surrogacy, a prohibition affecting donor gamete supplies could greatly limit this option. In the absence of ample supplies of donor eggs, the practice of surrogacy could be affected in two ways. First, the shortages could force a return to traditional surrogacy with the accompanying legal uncertainty. Second, individuals in need of surrogacy, but deterred by the legal uncertainty accompanying traditional surrogacy, could refrain from seeking surrogacy altogether or go overseas.

\section{A. Return to Traditional Surrogacy}

Under this first option, faced by shortages in donor eggs, individuals in need of both donor eggs and a surrogate could resort to using a traditional surrogate whose eggs would be

them, they feel they would have great emotional difficulty relinquishing a child that is biologically theirs). But see Olga B. A. Van Den Akker, $A$ Longitudinal Pre-Pregnancy to Post-Delivery Comparison of Genetic and Gestational Surrogate and Intended Mothers: Confidence and Genealogy, 26 J. Psychosomatic OBSTETRICs 277, 282 (2005) (finding that the majority of surrogates' beliefs regarding the importance of a genetic link depended on whether they were traditional or gestational surrogates.).

113 See generally AMERICAN SOCIETY FOR REPRODUCTIVE MEDICINE, supra note 10 , at 14 (including medical issues include a congenital absence of a uterus, a prior hysterectomy, an odd shaped, such as a tshaped uterus, a repetitive pregnancy loss, or a medical condition that is incompatible with pregnancy, such as a severe heart disease, lupus, or a history of breast cancer). 
used instead of the eggs of a third party. Surrogates have traditionally not been anonymous. Surrogates often maintain contact with the child and intended parents after the birth of the child. Furthermore, unlike parents using solely donor gametes, parents using surrogates usually tell their children about their conception method.114 Thus, prohibitions on gamete donor anonymity are unlikely to affect the availability of traditional surrogates in the way they could affect the supply of eggs.

A resort to traditional surrogacy could eradicate the progress made with the advent of gestational surrogacy, particularly in terms of increasing legal certainty within the practice of surrogacy. The shift to gestational surrogacy enhanced both legal certainty and diminished concerns that surrogates will change their minds. Practitioners prefer gestational surrogacy over traditional surrogacy, in part, because it offers legal certainty about parental status to all parties to the contract. ${ }^{115}$ As discussed, most states that

114 See S. Golombok, C. Murray et al., Non-Genetic and NonGestational Parenthood: Consequences for Parent-Child Relationships and the Psychological Well-Being of Mothers, Fathers and Children at Age 3, 22 HUM. REPROD. 1918, 1921 (2006) (comparing disclosure to donor-conceived children with that of disclosure to surrogacy conceived children); Andrea Mechanick Braverman \& Stephen L. Corson, A Comparison of Oocyte Donors' and Gestational Carriers/Surrogates' Attitudes Toward Third Party Reproduction 19 J. AssISTED REPROD. \& GENETICS 462, 465-66 (2002) (comparing attitudes toward disclosure and contact with born children between donors and surrogates); Fiona MacCallum et al., Surrogacy: The Experience of Commissioning Couples, 18 HUM. REPROD. 1334, 1339-1340 (2003) (reporting that 76\% of surrogates maintained contact with the family after birth and all commissioning couples reported that they intended to tell the child about the surrogacy arrangement); V. Javda et al., Surrogacy Families 10 Years On: Relationship with the Surrogate, Decisions Over Disclosure and Children's Understanding of Their Surrogacy Origins, 27 HUM. REPROD. 3008, 3010-11 (2012) (reporting that ten years after birth $90 \%$ of commissioning couples told the child about the surrogacy arrangement a majority of families were still in contact with the surrogate). Moreover, disclosure and contact persist voluntarily and not through a government enforcement mechanism. Even the few states that require surrogates to register keep all information secret. See, e.g., N.H. REV. STAT. ANN. §§ 168-B:21, B:24.

115 See Scott, supra note 86, at 122. 
allow surrogacy accord legal certainty only to gestational surrogacy. State legislatures and courts granted gestational surrogacy the legal certainty they would not grant traditional surrogacy, because traditional surrogacy was perceived as more immoral. Traditional surrogacy can be viewed as baby-selling, while gestational surrogacy is generally viewed as a cure for infertility. ${ }^{116}$ Lawmakers have viewed traditional surrogacy as an agreement in which the surrogate gives her child to the couple, while gestational surrogacy was viewed as an arrangement where the couple gives their child to the surrogate for gestation. Therefore, the former is seen as baby selling and the latter as a curing treatment. ${ }^{117}$

Gestational surrogates are viewed differently than traditional surrogates. Gestational surrogacy splits the genetic mother from the surrogate mother, thereby weakening the connection between the surrogate and the baby.118 Gestational surrogates are often described as 'carriers' and not mothers. The gestational surrogate's lack of a biological connection with the child she is carrying diminishes her identity as the child's mother, and instead is viewed as providing contractual gestational services to the actual parents. ${ }^{119}$ At the same time, traditional surrogates are seen as giving their child to another woman. Therefore, traditional surrogate is perceived as having a greater claim to the child than the intended mother. ${ }^{120}$

Given the current climate and perceptions of traditional surrogacy, a forced return to traditional surrogacy due to scarcity in donor eggs is likely to increase legal uncertainty for those involved in the practice of surrogacy. Furthermore, practitioners prefer gestational surrogacy not only because of the increased legal certainty, but also due to their belief

116 Noa Ben-Asher, The Curing Law: On the Evolution of BabyMaking Markets, 30 CARDOzo L. REV. 1885, 1888, 1914 (2009); see also Scott, supra note 86 , at 137 (arguing that the framing of surrogacy as baby selling has lost force as traditional surrogacy has been replaced by gestational surrogacy in recent years).

117 Id. at 1922.

118 See Spar, supra note 68 , at 79.

119 Scott, supra note 86, at 140-41.

120 See Spar, supra note 68 , at 78. 
that gestational surrogates are not genetically related to the baby and are less likely to change their minds and try to keep the baby. Gestational surrogates also appear to share the view that they are not connected to a baby that is not genetically theirs. Gestational surrogates often comment that: "[i]t's their baby, and I am just an incubator." 121 The convictions of all those engaged in the practice of surrogacy, gives rise to concern that a forced resort to traditional surrogacy will increase uncertainty due to a higher number of incidents in which surrogates will refuse to relinquish the baby once it is born.

\section{B. Refrain from Surrogacy Altogether}

Under the second option, individuals deterred by the uncertainty accompanying traditional surrogacy may refrain from resorting to surrogacy altogether or resort to seeking surrogacy services overseas. This could result in a significant contraction of the practice of surrogacy in the United States. ${ }^{122}$ Certainty is important and parties are more likely to enter agreements if they know that the law will compel enforcement. Legal certainty has played a pivotal role in the practice of surrogacy; for example "California surrogacy firms regularly advertise the state's receptivity to contractual reproductive arrangements," drawing infertile people from around the world. ${ }^{123}$ Faced with the sole option of traditional surrogacy with its ensuing uncertainty, individuals, for whom this is the only

121 See Scott, supra note 86, at 141 (2009); Claire Snowdon, What Makes a Mother? Interviews with Women Involved in Egg Donation and Surrogacy, 21 BIRTH 77, 83 (1994).

122 See generally Gaia Bernstein, The Socio-Legal Acceptance of New Technologies: A Close Look at Artificial Insemination, 77 WASH. L. REV. 1035, 1072-1083 (2002) (describing how legal risk delayed the adoption of the technology of artificial insemination).

123 Sanger, supra note 104, at 142; but cf, COUNCIL FOR RESPONSIBLE GENETICS, supra note 20, at 14-17 (demonstrating that states that did not legalize surrogacy and enforce surrogacy contracts still have a significant number of gestational surrogacy IVF cycles. For example, $5 \%$ of gestational surrogacy IVF procedures nationally are performed in New York - a state that prohibits and criminalizes surrogacy). 
option of having child genetically related to one of the partners, could be deterred from pursuing surrogacy.

Furthermore, eliminating the option of surrogacy enhances the pain of infertility. Numerous studies record the psychological effects of infertility on both men and women, for instance, infertility causes elevated levels of anxiety and depression, grief, anger, guilt and shock, or denial. ${ }^{124}$ Surrogacy is the only option for certain individuals to have a child who is genetically related to one partner. Individuals unable to have a genetically related child express sentiments such as: "[i]t is the end of the Bowes family and the Bowes Family name. It dies with us because of me. My husband is the last of the male children in his family ... it is the death of a dream . . ." 125

Thus, while the discussions regarding the impact of prohibitions on gamete donor anonymity usually center on the bests interests of the children, the privacy of the intended parents, the privacy of the donors and effects on gamete supplies, the relatively unique preference for gestational surrogacy in the United States adds additional concerns. Prohibitions on gamete donor anonymity can have the unintended consequences of disrupting the practice of surrogacy or enveloping it in additional uncertainty. And,

124 See, e.g., Colleen M. Padia, Infertility Takes Psychological Toll on Patients, URology TIMEs, Oct. 1, 2006, at 14 (reporting on two studies that found increased levels of anxiety and depression among infertile couples); T. Wischmann et al., Psychosocial Characteristics of Infertile Couples: $A$ Study by the 'Heidelberg Fertility Consultation Service,' 16 HUM. REPROD. 1753, 1760 (2001) (finding a high level of anxiety and depression particularly for infertile women); see also Christine Dunkel-Schetter \& Marci Lobel, Psychological Reactions to Infertility, in INFERTILITY: PERSPECTIVES FROM STRESS AND COPING RESEARCH 29, 30-35 (Annette L. Stanton \& Christine Dunkel-Schetter eds., 1991) (finding that the descriptive studies showed more adverse psychological effects as a result of infertility). But see Christine DunkelSchetter \& Marci Lobel, Psychological Reactions to Infertility, in INFERTLLITY: PERSPECTIVES FROM STRESS AND COPING RESEARCH 29, 5053 (Annette L. Stanton \& Christine Dunkel-Schetter eds., 1991) (finding that the empirical studies showed less adverse psychological effects as a result of infertility).

125 B.E. Menning, The Emotional Needs of Infertile Couples, 34 FERTILITY \& STERILITY 313, 317 (1980). 
although attitudes toward donor anonymity may change as the twenty-first century progresses, the reported data and potential ramifications for surrogacy advise toward great caution for those considering the implementation of an open identity system in the United States. Advocates contemplating a transition to an open identity system should consider the need to combine such a shift with a change to the legal structure, which currently gives gestational surrogacy a preferred legal status as it distinguishes between traditional and gestational surrogacy. ${ }^{126}$

\section{CONCLUSION}

Supporters of an open identity system for egg and sperm donors are advocating that the United States join a growing international trend of jurisdictions that prohibit gamete donor anonymity. This Article suggested that a shift to an open identity system should be considered with great caution. It showed that beyond the recognized interests that could be affected by a prohibition on anonymity, the potential impact of an open identity system on gamete donor supplies could affect a particular subset of infertility patients in the United States - those requiring both a donor egg and a surrogate to have a child. Unlike most other jurisdictions that prohibited anonymity, the practice of surrogacy in the United States is particularly vulnerable to prohibitions on gamete donor anonymity because most states that permit surrogacy recognize and accord legal certainty only to gestational surrogacy, which is highly dependent on donor eggs. The infertility industry has followed suit and also prefers gestational surrogacy to traditional surrogacy. A study of three foreign jurisdictions,

126 Noa Ben-Asher has called for abolishing the distinction between gestational surrogacy and traditional surrogacy because the preference for gestational surrogacy excludes low-income individuals and couples who can't afford IVF and gestational surrogacy. See Ben-Asher, supra note 116 , at 1918-1923. However, considering the role the shift toward the preferred status of gestational surrogacy has played in enhancing the legitimacy of surrogacy in the United States, a change away from this legal status is likely to involve significant complications. 
which implemented prohibitions on gamete donor anonymity, showed that these prohibitions played in a role in creating scarcity in donor eggs and sperm. This Article posits that a prohibition on anonymity could have a similar impact on donor gamete supplies in the United States and it underscores that depletion in donor gamete supplies could destabilize the practice of surrogacy. Since gestational surrogacy is highly dependent on donor eggs, it could either coerce a resort to traditional surrogacy with the enveloping legal uncertainty or it could deter infertility patients from seeking surrogacy altogether greatly contracting the practice of surrogacy. Thus, this Article cautions that consideration of the potential impact on the practice of surrogacy should be taken into account, among other interests, in considering a shift toward an open identity system. 